\title{
Application of Linear Programming Algorithm in the Optimization of Financial Portfolio of Golden Guinea Breweries Plc, Nigeria
}

\author{
Emmanuel Nwabueze Ekwonwune1, Dominic Chukwuemeka Edebatu2 \\ ${ }^{1}$ Department of Computer Science, Imo State University, Owerri, Nigeria \\ ${ }^{2}$ Department of Computer Science, Nnamdi Azikiwe University, Awka, Nigeria \\ Email: ekwonwuneemmanuel@yahoo.com
}

Received 8 April 2016; accepted 17 June 2016; published 20 June 2016

Copyright $(2016$ by authors and Scientific Research Publishing Inc.

This work is licensed under the Creative Commons Attribution International License (CC BY). http://creativecommons.org/licenses/by/4.0/

(c) (i) Open Access

\begin{abstract}
In this study, Simplex Method, a Linear Programming technique was used to create a mathematical model that optimized the financial portfolio of Golden Guinea Breweries Plc, Nigeria. This work was motivated by the observed and anticipated miscalculations which Golden Guinea Breweries was bound to face if appropriate linear programming techniques were not applied in determining the profit level. This study therefore aims at using Simplex Method to create a Mathematical Model that will optimize the production of brewed drinks for Golden Guinea Breweries Plc. The first methodology involved the collection of sample data from the company, analyzed and the relevant coefficients were deployed for the coding of the model. Secondly, the indices collected from the first method were deployed in the software model called PHP simplex, an online software for solving Linear Programming Problem to access the profitability of the organization. The study showed that Linear Programming Model would give a high profit coefficient of N9,190,862,833 when compared with the result obtained from the manual computation which gave a profit coefficient of N7,172,093,375. Also, Bergedoff Lager, Eagle Stout and Bergedoff Malta were found not to contribute to overall profitability of the company and it was therefore recommended that their productions should be discontinued. It also recommends that various quantities of Golden Guinea Lager $(1 \times 12)$ and Golden Guinea Lager $(1 \times 24)$ should be produced.
\end{abstract}

\section{Keywords}

Optimization, Linear Programming, Model, Products, Software, Linear Programming Model 


\section{Introduction}

Golden Guinea Breweries Plc, Nigeria is a production company that produces drinks (beers and malt) for daily human consumption. Given the method and volume of production and sale, raw materials which are used for the production of these beers and malt are often supplied on credit while suppliers or creditors are paid in later days according to company's policy. Moreover, other transactions such as repairing of broken down machines and the like are also done on credit. Since these transactions are done as time and need arise, it therefore becomes necessary that a system should be adopted whereby transactions are categorized with the aim of improving the efficiency of payment appropriately. In light of this, an automated information system has been developed with high level of control as regards modification and timely rendering of accurate reports to functional managers for result oriented decision-making.

One of the main issues that management of companies and institutions deals with is permanent optimization and improvement of its main process of production. Given the fact that the solution to one problem can be done in many ways, it is important to find and implement the optimal solution between them. In the view of Taha $\mathrm{H}$. A. [1], Mathematical Programming is special mathematical approach of selecting the best/optimal from the set of possible alternatives towards solving the problem. It assumes that it is possible to represent the problem as a Mathematical Model that reflects certain production function (more precisely, mathematical function). In this direction, resolution of the problem of optimization converges to determination of the optimal (minimum or maximum, depending on the nature of the model) value of the production function, having in mind all the limitations of the model/environment, represented in the limitation equations.

The development of the automated system went through stages like system analysis, design and implementation of the results.

\subsection{Related Work}

Linear programming has been widely applied in Breweries, as most managerial problems involve resource allocation. For example, management decision problems such as production planning, capital budgeting, personnel allocation, advertising and promotion planning are concerned with the achievement of a given objective (profit maximization or cost minimization) subject to limited resources (money, material, labor, time, etc.).

Linear programming, sometimes known as linear optimization, is the problem of maximizing or minimizing a linear function over a convex polyhedron specified by linear and non-negativity constraints. Simplistically, Sul$\tan$ A. [2], states that Linear Programming is the optimization of an outcome based on some set of constraints using a linear mathematical model. According to Symorg [3], Linear programming is implemented in the Wolfram Language as Linear Programming $[c, m, b]$, which finds a vector $\boldsymbol{x}$ which minimizes the quantity $c \boldsymbol{x}$ subject to the constraints $m \boldsymbol{x} \geq b$ and $x_{i} \geq 0$ for $x=\left(x_{1}, \cdots, x_{n}\right)$. According to Wikipedia [4], linear programming is a technique for the optimization of a linear objective function, subject to linear equality and linear inequality constraints. It's feasible region is a convex polytope, which is a set defined as the intersection of finitely many half spaces, each of which is defined by a linear inequality. Its objective function is a real-valued affine function defined on this polyhedron. A linear programming algorithm finds a point in the polyhedron where this function has the smallest (or largest) value if such a point exists. Linear programming is the best known and one of the most widely used techniques of management science. It is a mathematical technique for determining the best allocation of a firm's limited resources. In his own contribution, Wagner H.M. [5], is of the view that Linear programming involves the description of a real world decision situation as a mathematical model that consists of a linear objective function and linear resource constraints. According to Iwuagwu C.C. [6], Linear Programming is also special technique for determining the optimum combination of scarce resources in the attainment of some objectives of economic or other nature. Iwuagwu contends that it is a method for solving problems in which an objective function must be maximized or minimized when considering certain constraints. Iwuagwu further stated that Linear programming follows the following steps to transform life problem in industries into linear programming solution as shown below:

- Firstly, it determines the quality to be optimized (minimized and or maximized) and expresses it as a mathematical function called criterion function or objective function.

- Secondly, it identifies all stipulated requirements, restrictions and limitations and expresses them mathematically.

- Thirdly, it expresses any hidden conditions; such conditions are not stipulated explicitly in the problem but 
are apparent from the physical situation being modeled.

- There must be a well defined objective function such as profit, cost or revenue functions.

- There must be different alternative courses of action for linear programming to be applied.

- Linearity in linear programming is a mathematical term used to describe systems of simultaneous equations of the first degree which satisfy the objective function and constraints.

- The resources which must be limited in supply are finite and economically quantifiable [6].

Furthermore, Iwuagwu [6], is of the opinion that the following steps should be adopted in formulating a linear programming model:

- Identification of the decision variables.

- Identification of the objective function which may be profit, revenue or cost functions and expressing it as an equation.

- Identification of the constraints and expressing them in the form of inequalities. The constraints should express the usage of available resources.

- Write the standard Linear programming model.

In their contributions, Andersen E.D. and Anderson K.D. [7], contend that the simplex algorithm, invented by George Dantzig in 1947, is one of the earliest and best known optimization algorithms. The algorithm solves the linear programming problem

$$
\min _{x} f^{T} x \text { such that }\left\{\begin{array}{l}
A \cdot x \leq b \\
\text { Aeq } \cdot x=b e q, \\
l b \leq x \leq u b .
\end{array}\right.
$$

The algorithm moves along the edges of the polyhedron defined by the constraints, from one vertex to another, while decreasing the value of the objective function, $f^{T} x$, at each step. They contend that the simplex algorithm has two phases:

Phase 1-Compute an initial basic feasible point. Here, the algorithm finds an initial basic feasible solution by solving an auxiliary piecewise linear programming problem. The objective function of the auxiliary problem is the linear penalty function $P=\sum_{j} P_{j}\left(X_{j}\right)$

- where $P_{j}\left(X_{j}\right)$ is defined by

- $P_{j}\left(X_{j}\right)= \begin{cases}x_{j}-u_{j} & \text { if } x_{j}>u_{j} \\ 0 & \text { if } l_{j} \leq x_{j} \leq u_{j} \\ l_{j}-x_{j} & \text { if } l_{j}>x_{j}\end{cases}$

$P(x)$ measures how much a point $x$ violates the lower and upper bound conditions. The auxiliary problem is $\min _{x} \sum_{j} P_{j} \quad$ subject to $\left\{\begin{array}{l}A . x \leq b \\ \text { Aeq } \cdot x=\text { beq. }\end{array}\right.$

Phase 2. Compute the optimal solution to the original problem. Here, the algorithm applies the simplex algorithm, starting at the initial point from phase 1 , to solve the original problem. At each iteration, the algorithm tests the optimality condition and stops if the current solution is optimal.

Robert et al. [8], is of the view that Karmarkar's algorithm is rather complicated as shown below:

Algorithm Affine-Scaling

Input: $A, b, c, x^{0}$, stopping criterion, $\gamma$.

$$
k \leftarrow 0
$$

do while stopping criterion not satisfied

$$
\begin{aligned}
& v^{k} \leftarrow b-A x^{k} \\
& D_{v} \leftarrow \operatorname{diag}\left(v_{1}^{k}, \cdots, v_{m}^{k}\right) \\
& h_{x} \leftarrow\left(A^{T} D^{-2} A\right)-1_{C} \\
& h_{v} \leftarrow-A h_{x} \\
& \text { if } h_{v} \geq 0 \text { then } \\
& \text { return unbounded }
\end{aligned}
$$




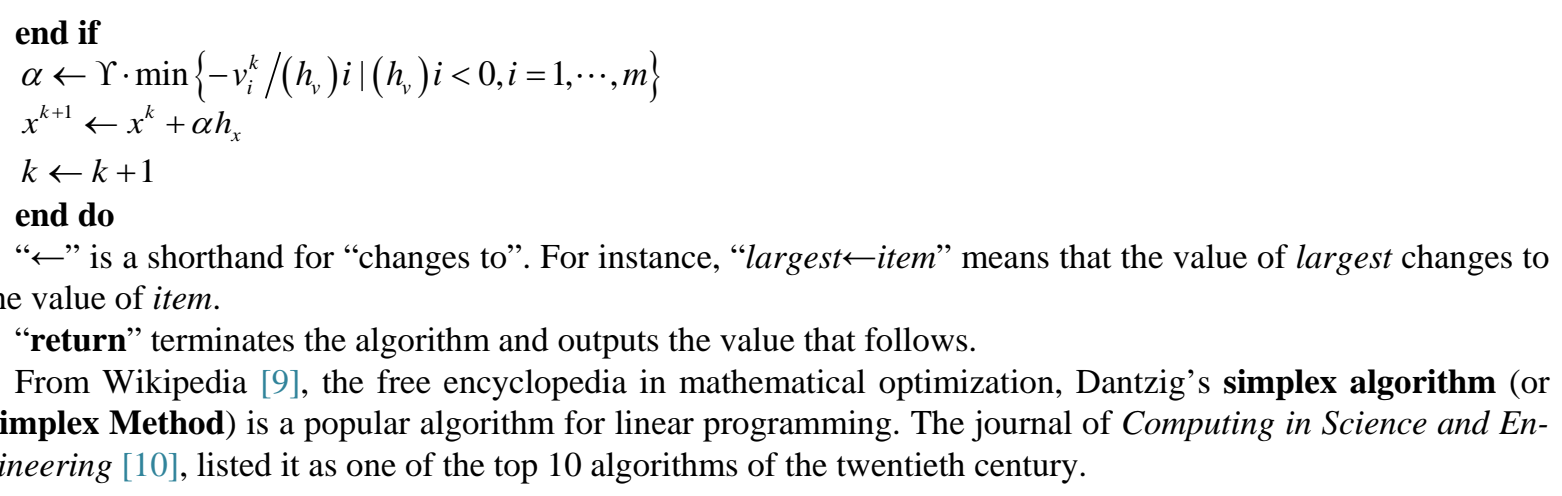

\subsection{Statement of Problem}

In recent times, Golden Guinea Breweries has been faced with low profitability as a result of miscalculations, probably at the managerial level. This has no doubt generated numerous problems in the company. Some of these problems include delay in payment of salaries and wages, inadequate provision of motivational benefits in the work place, laissez-faire attitude to work by the employees and reduced productivity, etc. As a result of the forgoing problems, there is unhappiness in the minds of staff, frustration, insecurity, high staff turn-over, high recruitment and training rates, low profit potential of the organization. Staff who are not well remunerated feel unsatisfied with the organization and this creates tension and anxiety within them. Tension and anxiety result to aggressiveness over companies polices. These problems also lead to frustration among workers, conflicts of roles, confusion and complaints, etc. Job insecurity results when worker's expectations are not met. This leads to an employee leaving the organization at any slightest chances in search of better job. Those who stay would have laissez-faire attitudes in doing their jobs. Therefore, a study that scientifically investigates and provides ways of optimizing the financial portfolio of Golden Guinea is highly imperative.

\subsection{Objective of Study}

This study aims at using Simplex Method, one of the Linear Programming Techniques to create a Mathematical Model that will optimize the profit of the production of Brewed drinks for Golden Guinea Breweries Plc.

\section{Methodology}

The various data we are primarily concerned with are the following:

1) Cost of production.

2) Total sales incomes.

3) Raw materials and their cost per annum.

4) The price of a unit (one carton) of the products.

Also, Listed below is the summary of the products of the company;

1) Golden Guinea $(1 \times 12)$ lager, G.G $(1 \times 12)$.

2) Golden Guinea $(1 \times 12)$ lager, G.G $(1 \times 24)$.

3) Bergerdoff lager (BDF).

4) Eagle stout (E/S).

5) Bergerdoff malta (B/M).

\section{Research Procedure}

According to Anyanwu A. [11], the research procedure centers mainly on the data collection and simplification. As earlier stated, data collection for this study was through interview method which yielded data through verbal interaction and questionnaire distributed among members and staff of the organization under study. The company has four major departments: Production, Purchasing, Accounting and Finance and Marketing departments. The production process involves the transformation of raw material through various stages both manual and machine oriented to get the finished products. The data collected include: 
- The products of the company.

- The total cost of production for each product.

- The prices of a unit (one carton) of the product.

- The sales income for each product.

- The total sales revenue for each product.

- The raw materials for each product.

- The total cost of raw material.

- The machines used at different stages.

\section{The Model}

According to Ekwonwune E.N., [12] a Linear Programming Model is of the form:

Minimize or Maximize $Z=\sum_{j=1}^{n} C_{j} X_{j}$

Subject to: $=\sum_{i=1} \sum_{j=1} A_{i j} X_{j}(<=>) b_{i}$

The annual cost of raw material per unit of production can be gotten by dividing the total cost of raw materials per annum by the total quantity produced as shown in Table 1 .

Objective Function

The research problem bothers on how to optimize the production system. We define the profit contribution of a unit of each of the product and aim at getting the quantity of each product that will maximize the profit from the system.

We define the quantities of the five products that will maximize profit to the decision variables. Hence we have the following:

$\mathrm{X}_{1}=$ The quantity of Golden Guinea Lager $(1 \times 12)$ in cartons.

$\mathrm{X}_{2}=$ The quantity of Golden Guinea Lager $(1 \times 24)$ in cartons.

$\mathrm{X}_{3}=$ The quantity of Bergedoff Lager in cartons.

$\mathrm{X}_{4}=$ The quantity of Eagle stout in cartons.

$\mathrm{X}_{5}=$ The quantity of Bergedoff Malta in cartons.

Hence, the Objective function then transforms to:

Maximize $Z=66.6 x_{1}+96.5 x_{2}+60.5 x_{3}+218.7 x_{4}+104.4 x_{5}$

\section{Raw Material Constrains}

In this study, the cost of raw materials constitutes the major constraints. This is because the system operates in an open market; that is, there is a ready market for as much as they can produce. Also since the machines used run a long lifecycle, they work as long as they remain on and as such have no maximum capacity.

The cost of raw materials and the production in general constitute the constraint in production. The cost of raw materials for a unit of production as shown in Table 2 is expressed thus:

Sorghum: $21.144768 x_{1}+0.071741 x_{2}+7.721884 x_{3}+4.0005 x_{4}+20.968132 x_{5} \leq 53.907025$

Sugar: $0.300000 x_{5} \leq 0.300000$

Enzymes: $7.218816 x_{1}+0.024493 x_{2}+4.966576 x_{3}+2.544372 x_{4}+1.245227 x_{5} \leq 15.999484$

Hops: $0.005190192 x_{1}+0.017612 x_{2}+3.421288 x_{3}+0.900576 x_{4}+3.536607 x_{5} \leq 7.881273$

Brewing sundries: $7.935048 x_{1}+0.026933 x_{2}+2.990746 x_{3}+0.342768 x_{4}+11.068012 x_{5} \leq 22.363507$

Bottling and washing machine:

$22.84128 x_{1}+0.119559 x_{2}+11.700076 x_{3}+2.857844 x_{4}+20.551603 x_{5} \leq 58.070362$

Table 1. Total and unit costs of production and profit contribution.

\begin{tabular}{ccccc}
\hline Product & Total Cost of Production $(\mathrm{N})$ & Quantity & Unit profit Contribution (per Carton) & Unit Cost of Production (N) \\
\hline G.G $(1 \times 12)$ & $183,519,571$ & 1636,928 & N66.62 & 112.11 \\
G.G $(1 \times 24)$ & 699,152 & 5546 & N96.48 & N60.51 \\
BDF Lager & $74,542,130$ & 581,900 & N218.73 & 126.06 \\
E/S & $26,410,369$ & 109,147 & N104.42 & 128.10 \\
B/M & $147,421,163$ & 952,150 & & 241.97 \\
\hline
\end{tabular}

Source: [12]. 
Table 2. Total cost of material (millions).

\begin{tabular}{|c|c|c|c|c|c|}
\hline Raw Material & G.G $(1 \times 12)$ & G.G $(1 \times 24)$ & BDF & E/S & $\mathbf{B} / \mathbf{M}$ \\
\hline Sorghum & 21.144768 & 0.071741 & 7.721884 & 4.0005 & 20.968132 \\
\hline Sugar & 0 & 0 & 0 & 300000 & 300000 \\
\hline Enzymes & 7.218816 & 0.024493 & 4.966576 & 2.544372 & 1.245227 \\
\hline Hops & 0.005190 & 0.017612 & 3.421288 & 0.900576 & 3.536607 \\
\hline Brewing Sundries & 7.935048 & 0.026933 & 2.990746 & 0.342768 & 11.068012 \\
\hline Bottling and Washing Materials & 22.84128 & 0.119559 & 11.700076 & 2.857844 & 20.551603 \\
\hline
\end{tabular}

Source: [12].

Total cost of production results from material, personnel and miscellaneous costs as shown below:

Total Cost of production $=$ Cost of materials + Personnel Cost + Miscellaneous Cost .1

Table 3 shows that Total production cost gives sum of Cost of materials, personnel and miscellaneous costs. It also shows that Total Profit is given as:

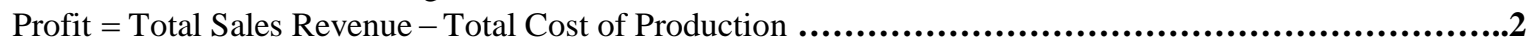

The Total Cost of Production Constraint

Since the other expenses also contribute to the total cost of production of each of the production, the total cost of production hence constitutes the constraint,

$112.1 x_{1}+126.1 x_{2}+128.1 x_{3}+242 x_{4}+154.8 x_{5} \leq 432592358$

The Complete Model

Having defined the criterion function, decision variable and constraints, our model is given as shown below thus;

Maximize $P=66.6 x_{1}+96.5 x_{2}+60.5 x_{3}+218.7 x_{4}+104.4 x_{5}$

Subject to:

$21.144768 x_{1}+0.071741 x_{2}+7.721884 x_{3}+4.0005 x_{4}+20.968132 x_{5} \leq 53.907025$

$0.300000 x_{5} \leq 0.300000$

$0.005190192 x_{1}+0.017612 x_{2}+3.421288 x_{3}+0.900576 x_{4}+3.536607 x_{5} \leq 7.881273$

$7.935048 x_{1}+0.026933 x_{2}+2.990746 x_{3}+0.342768 x_{4}+11.068012 x_{5} \leq 22.363507$

$22.84128 x_{1}+0.119559 x_{2}+11.700076 x_{3}+2.857844 x_{4}+20.551603 x_{5} \leq 58.070362$

$0.0001121 x_{1}+0.0001261 x_{2}+0.0001281 x_{3}+0.000242 x_{4}+0.0001548 x_{5} \leq 432.592358$

\section{Analysis}

The various data obtained are used in the PHP Simplex. The steps taken in using the Simplex Method to solve our model are shown below:

The leaving variable is $\mathrm{P}_{8}$ and entering $\mathrm{P}_{4}$.

The indices collected from the section of the complete model were deployed in the PHP simplex. A close look shows that the initial tableau is shown in Table 4 while the final tableau is shown in Table 5 . One also observes that the overall profit from the final tableau is the optimal solution given by N9, 190, 862, 855.

Show results as fractions

The optimal solution value is $\mathrm{Z}=9190.862855157$.

$\mathrm{X}_{1}=0.20031389501087$.

$\mathrm{X}_{2}=44743546061916$.

$\mathrm{X}_{3}=0$.

$\mathrm{X}_{4}=0$.

$\mathrm{X}_{5}=0$.

The optimal solution value is $Z=9,190,862,855$.

$X_{1}=200,313$.

$\mathrm{X}_{2}=447,435,460$.

$\mathrm{X}_{3}=0$.

$\mathrm{X}_{4}=0$.

$\mathrm{X}_{5}=0$ 


\section{Discussion}

From the above result, it is clear that the profit, N7, 172,093,575 obtained from Table 3 is different from that, $\mathbf{N 9 , 1 9 0 , 8 6 2 , 8 5 5}$ obtained using the Simplex Software as shown in Table 5. One of the reasons that account for low profitability in the manual methods is that not every variable is put into consideration in the process of computation. Also the optimal solution using Linear Programming Model rejects three variables $\mathrm{X}_{3}, \mathrm{X}_{4}$ and $\mathrm{X}_{5}$ respectively but their consideration in the manual method resulted to considerable loss in market value.

The various quantities of the cartons of each of the products of the company that should be produced per annum for the optimal profit obtained in section 3.0 are such that:

1) 200,312 of Golden Guinea Lager $(1 \times 12)$ will be produced.

2) $447,435,460$ cartons of Golden Guinea lager $(1 \times 24)$ will be produced.

3) No quantity of Bergedoff Lager will be produced.

4) No quantity of Eagle stout will be produced.

5) No quantity of Bergedoff Malta will be produced.

From the result above, it will be observed that three products whose production should be stopped for the optimal system are $\mathrm{X}_{3}=$ Golden Guinea $(1 \times 12), \mathrm{X}_{4}=$ Bergedoff Lager and $\mathrm{X}_{5}=$ Bergedoff Malta with the least unit profits contributions. Also from our model, it is obvious that surplus amounts will result which is brought about by the reduction in the cost of production and this helps to boost the profits.

\section{Conclusions and Recommendation}

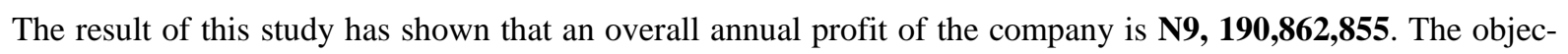
tive of this study was to be able to plan production for the company for a period of one year in order to maximize profit. The system model hence is able to:

1) Maximize profit, 2) Allocate raw materials, and 3) Deduce an optimal cost of production. 4) All excesses from cost of raw materials and other expenditure that were cut down generally affected the cost of production and an optimal amount was reached.

Table 3. The total sales revenue, total cost of production and total profit contribution.

\begin{tabular}{cccc}
\hline Product & Total Sales Revenue & Total Cost of Production & Total Profit Contribution \\
\hline G.G $(1 \times 12)$ & $2,272,569,600$ & $183,519,571$ & $2,089,050,029$ \\
G.G $(1 \times 24)$ & $981,234,260$ & 699,152 & $980,535,108$ \\
BDF & $1,091,752,700$ & $74,542,130$ & $1,017,210,570$ \\
E/S & $1,030,284,000$ & $26,410,369$ & $1,003,873,631$ \\
B/M & $2,228,845,400$ & $147,421,163$ & $2,081,424,237$ \\
Total & $\mathbf{7 , 6 0 4 , 6 8 5 , 9 6 0}$ & $\mathbf{4 3 2 , 5 9 2 , 3 8 5}$ & $\mathbf{7 , 1 7 2 , 0 9 3 , 5 7 5}$ \\
\hline
\end{tabular}

Source: [12].

Table 4. The initial tableau.

\begin{tabular}{|c|c|c|c|c|c|c|c|c|c|c|c|c|c|c|}
\hline Tableau 1 & & & 66.6 & 96.5 & 60.5 & 218.7 & 104.4 & 0 & 0 & 0 & 0 & 0 & 0 & 0 \\
\hline Base & $\mathrm{C}_{\mathrm{b}}$ & $\mathrm{P}_{0}$ & $\mathrm{P}_{1}$ & $\mathrm{P}_{2}$ & $\mathrm{P}_{3}$ & $\mathrm{P}_{4}$ & $\mathrm{P}_{5}$ & $\mathrm{P}_{6}$ & $\mathrm{P}_{7}$ & $\mathrm{P}_{8}$ & $\mathrm{P}_{9}$ & $\mathrm{P}_{10}$ & $\mathrm{P}_{11}$ & $\mathrm{P}_{12}$ \\
\hline P6 & 0 & 53.907025 & 21.144768 & 0.071741 & 7.721884 & 4.0005 & 20.968132 & 1 & 0 & 0 & 0 & 0 & 0 & 0 \\
\hline P7 & 0 & 0.3 & 0 & 0 & 0 & 0 & 0.3 & 0 & 1 & 0 & 0 & 0 & 0 & 0 \\
\hline P8 & 0 & 15.999484 & 7.218816 & 0.024493 & 4.966576 & 2.544372 & 1.245227 & 0 & 0 & 1 & 0 & 0 & 0 & 0 \\
\hline P9 & 0 & 7.881273 & 0.005190192 & 0.017612 & 3.421288 & 0.900576 & 3.536607 & 0 & 0 & 0 & 1 & 0 & 0 & 0 \\
\hline P10 & 0 & 22.363507 & 7.935048 & 0.026933 & 2.990746 & 0.342768 & 11.068012 & 0 & 0 & 0 & 0 & 1 & 0 & 0 \\
\hline P11 & 0 & 58.070362 & 22.84128 & 0.119559 & 11.700076 & 2.857844 & 20.551603 & 0 & 0 & 0 & 0 & 0 & 1 & 0 \\
\hline $\mathrm{P} 12$ & 0 & 432.592358 & 0.0001121 & 0.0001261 & 0.000242 & 0.000242 & 0.0001548 & 0 & 0 & 0 & 0 & 0 & 0 & 1 \\
\hline $\mathbf{Z}$ & & 0 & -66.6 & -96.5 & -218.7 & -218.7 & -104.4 & 0 & 0 & 0 & 0 & 0 & 0 & 0 \\
\hline
\end{tabular}




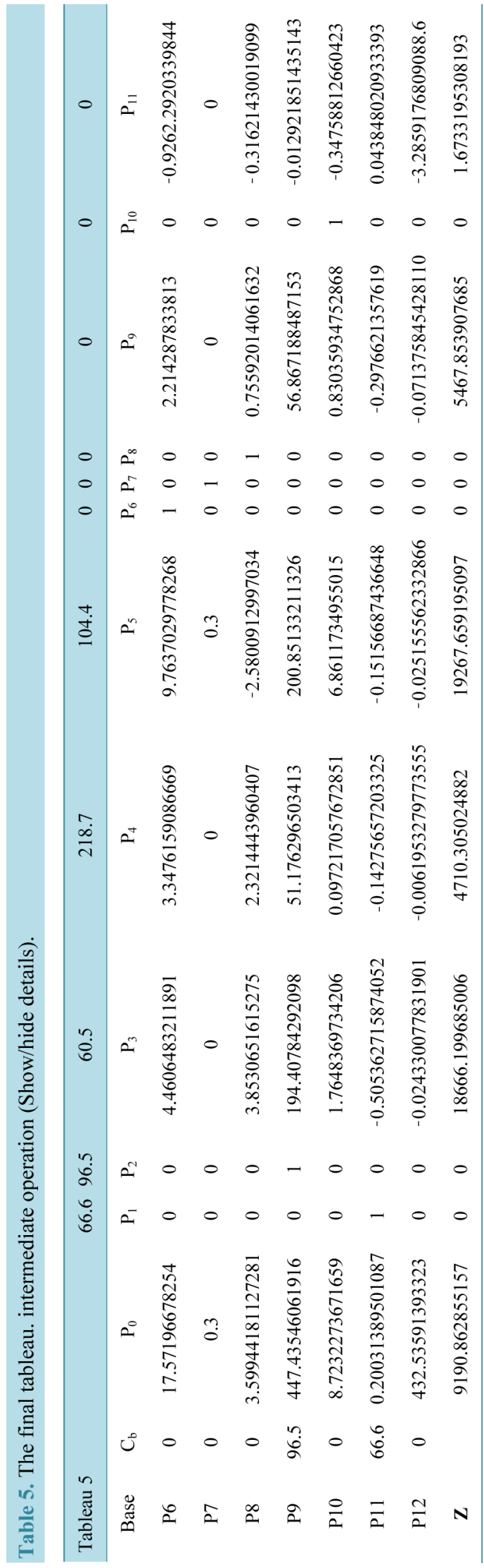


Following the result of this study, the following recommendations are hence given to Golden Guinea Breweries Plc:

- The quantities of the two products that should be increased for an optimal profit are: 200,312 cartons of Golden Guinea $(1 \times 12)$ Lager and 447,436,460 cartons of Golden Guinea $(1 \times 24)$ Lager beer.

- No production of Bergedoff lager beers, Eagle Stout and Bergedof Malta. Production should concentrate on the products that yield a high amount of profit.

- To maintain this optimal production level, there is a reduction in the cost of production, which helps boost the profit margin. This surplus amount should be plugged back into production in order to achieve a higher production level.

More awareness should be created for better appreciation of the products by the public. This will make for proper pricing of the products especially as regards the three products: Bergedoff Lager Beer, Eagle Stout and Bergedoff Malta respectively.

- Since machines run a long life cycle, their maintenance and servicing should be ensured so that they don’t break down unexpectedly and affect production.

\section{References}

[1] Taha, H.A. (2007) Operational Research Introduction. Pearson Education, Inc., Upper Saddle River.

[2] Sultan, A. (1993) Linear Programming: An Introduction with Applications. Academic Press, San Diego.

[3] Symorg (2014) Effectiveness Determination of Higher Education Using Linear Programming.

[4] https://en.wikipedia.org/wiki/Linear_Programming

[5] Wagner, H.M. (1975) Principles of Operation Research. Prentice Hall Inc., Englewood Cliff.

[6] Iwuagwu, C.C. (2000) Quantitative Methods for Business Application. Name Ventures Ltd., Owerri.

[7] Anderson, E.D. and Anderson, K.D. (1995) Presolving in Linear Programming. Math Programming.

[8] Robert, J.V., et al. (1986) The Modification of Karmarkar’s Linear Programming Algorithm. Algorithmica, 1, $395-407$. http://dx.doi.org/10.1007/BF01840454

[9] https://en.wikipedia.org/wiki/Simplex_algorithm

[10] Computing in Science and Engineering Volume 2, No. 1, 2000 html Version. http://www.computer.org.csdl/mags/cs/2000/01/c1022.html

[11] Anyanwu, A. (1994) Data Collection and Analysis. Avan Global Publication, Owerri.

[12] Ekwonwune, E.N. (2000) The Design and Development of a Linear Programming Model as a Tool for Decision Making Support in a Production Firm. An Unpublished M.Sc Thesis, Ekpoma University, Ekpoma. 